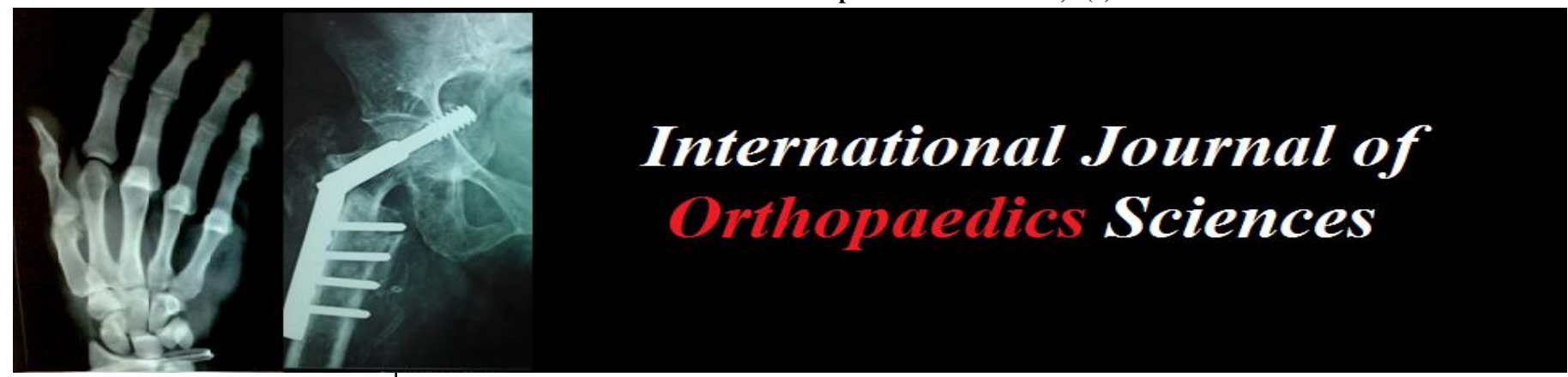

ISSN: $2395-1958$

IJOS 2018; 4(2): 496-500

(C) 2018 IJOS

www.orthopaper.com

Received: 16-02-2018

Accepted: 17-03-2018

Dr. Y Devadoss

M.S. Ortho, Assistant Professor, Dept. of Orthopaedics, AIMSR,

Chittoor, Andhra Pradesh, India

Dr. Shail Patel

Senior Resident, Dept. of

Orthopaedics, MIOT

International, Chennai,

Tamil Nadu, India

Dr. Joel Prasad GL

Senior Resident, Dept. of

Orthopaedics, MIOT

International, Chennai, India
Correspondence

Dr. Y Devadoss

M.S. Ortho, Assistant Professor,

Dept. of Orthopaedics, AIMSR,

Chittoor, Andhra Pradesh, India

\section{A prospective study on functional outcome of fracture shaft of femur stabilised with reamed intramedullary nail}

\section{Dr. Y Devadoss, Dr. Shail Patel and Dr. Joel Prasad GL}

\section{DOI: https://doi.org/10.22271/ortho.2018.v4.i2h.76}

\section{Abstract}

The incidence of femoral shaft fractures is on rise because of fast, high speed transportation and modern lifestyles. Internal fixation is the mainstay of treatment. Conventional plating is associated with high risk of infection, pseudoarthrosis, malunion, decreased knee motion and loss of fixation. Interlocking techniques lead to fewer complications of nonunion/malunion, lesser soft tissue dissection, earlier fracture healing and lesser chances of infection. Fractures in any zone from the subtrochanteric to distal supracondylar part of the femur are accessible to nailing.

Materials and Methods: This was a prospective study of patients who underwent reamed intramedullary nailing for the fracture shaft of the femur. All patients were operated by the same surgeon and patients were followed up to six months period at regular intervals. Functional outcome is assessed by Thoresen's criteria and lower extremity functional scoring system. The study shall be of two and half years duration with effect from May 2015 to October 2017. Post operative evaluation was done at 1 month, 3 months and 6 months following surgery.

Results: In our series of 78 cases of femoral shaft fractures treated by interlocking nail 57 patients had good outcome, 12 patients had moderate outcome, 5 had fair and 4 patients had poor outcome. Most of the patients in this series were younger age group; more than $80 \%$ were below 50 years.

Conclusion: We confirm that the functional outcome after fracture shaft of femur stabilised by reamed intramedullary nail is good to moderate. Intramedullary nailing is effective treatment for the stabilisation of the fracture shaft of femur in view of subjective and objective perspective. Femur interlocking nail is a good implant for the treatment of femoral shaft fractures because of its load sharing, closed insertion, rotational stability, restoration of anatomic length alignment and early mobilization.

Keywords: Fracture shaft of femur, intramedullary nailing of femur, interlocking system

\section{Introduction}

Femur is one of the strongest and longest bones in human body. The name femoral shaft was given to an area extending from $2 \mathrm{~cm}$ below lesser trochanter to $5-6 \mathrm{~cm}$ above femoral condyles. Femoral shaft fractures most often will be a result of high energy trauma in young adults and they are the major cause of morbidity and mortality. Morbidity arises from femoral shortening, mal alignment and quadriceps contracture and knee stiffness. Mortality is infrequent but can result due to open wounds, fat embolism or multiple organ failure in polytrauma. Femoral shaft fracture also causes marked alteration in bio-mechanics of gait and weight bearing. Therefore an appropriate stabilization device for femoral shaft fracture is essential to avoid the above said difficulties for an individual who sustains femoral shaft fracture.

Surgical stabilization of femoral shaft fracture is the gold standard in its management world over. The art and science of internal fixation for femoral shaft fractures has tremendously advanced over recent years. From the use of external splints in the Hippocratic age to sophisticated instrumentation, several orthopaedic scientists has greatly facilitated the surgical stabilization of femoral shaft fractures more so its expanded application to comminuted, segmental and spiral fractures of femur irrespective of the level of injury. The pioneering work of medullary nailing in 1930's and 1940's by Gerhard Kuntscher in Germany has revolutionized the management of femoral shaft fractures. 
The dissemination of intra medullary nailing technique by Kuntscher throughout the industrialized world has profoundly changed the outcome of the treatment of femoral shaft fractures. Intramedullary nail being close to center of femur can tolerate bending and torsional loads better than plates. IM interlocking nail is a load sharing device and causes less cortical osteopenia of stress shielding which is a feature of the load bearing plates. Closed nailing prevents damage to extra periosteal soft tissues and the biological environment round the fracture is least disturbed.

Our present study attempts to analyze the effectiveness of closed interlocking nailing (reamed) in the management of fracture shaft of femur so as to restore the patients to functionally and structurally to near normal status.

\section{Materials and Methods}

This Prospective observational analytical study was carried out on patients of Department of Orthopaedic surgery, patients who presented to, AIMSR, Chittoor, Andhra Pradesh between 1-January 2016 to 31-May-2017. 78 adult patients with femoral shaft fractures were selected for the present study. Post operative evaluation was done at 1 month, 3 months and 6 months following surgery.

\section{Operative Procedure}

Under the effect of the anesthesia patient was positioned lateral on the operating table. Hip flexed to about 15 degrees. Incision is centered on the tip of the greater trochanter and extended $4 \mathrm{~cm}$ proximally and slightly posterior, distal extension carried out if necessary. Using the $\mathrm{C}$ arm image intensifier, entry was made at the piriform fossa using $16 \mathrm{~mm}$ $\mathrm{k}$ wire. Entry point was confirmed both in the AP and lateral views. Ball tipped guidewire was inserted through the entry point passed upto the fracture site closed reduction achieved using manual traction and manipulation. This was confirmed by image intensifier in both the views. Reaming of the medullary canal is done in $1 \mathrm{~mm}$ increments using flexible intramedullary reamers and reaming was done $0.5 \mathrm{~mm}$ extra compared to the intended diameter of the nail to be used. Desired sized diameter of the nail was introduced to the canal. Desired nail was mounted onto the proximal jig. Fracture was reduced under the $\mathrm{c}$ arm guidance and constant traction and manipulation by the assistant. Nail was introduced to the fracture site to the distal segment.

After assembling the selected nail to jig it is introduced as far as possible manually into the medullary canal with the help of the mounted insertion instruments. Using the image intensifier by gentle blows with a hammer nail is counter sunk in the bone passing through fracture line. Nail entry was confirmed in both AP and lateral planes. Distal static locking done using freehand technique under $\mathrm{C}$ arm imaging. Locking of the bolts were checked in both the views. The cortex was drilled using a $4 \mathrm{~mm}$ drill bit and $4.5 \mathrm{~mm}$ locking bolts were inserted. Proximal locking was done using the proximal jig it was dynamic or static locking depending on the fracture pattern. The cortex was drilled using a $4 \mathrm{~mm}$ drill bit and $4.5 \mathrm{~mm}$ locking bolts were inserted. Wound closed in layers over continuous suction drain.

\section{Post-Operative Protocol}

Post-operative period drain was removed once it was below $30 \mathrm{ml}$.

Post operatively Injection Cefoperazone and Sulbactum 1.5 gm two doses were given for closed fractures. For compound fractures injection Metronidazole $500 \mathrm{mg}$ TDS IV in combination with Piperacillin-Tazobactum 4.5 gm IV TDS was administered. The antibiotics were then changed according to the culture and sensitivity reports and was continued till 5 days post op.

Injection low molecular weight heparin $0.4 \mathrm{ml} \mathrm{SC}$ was given till mobilization was started. It was then changed to tab. Aspirin $75 \mathrm{mg}$ at the time of discharge for 2 weeks.

Post-operative weight bearing protocol was changed according to the fracture pattern. On follow up visits weight bearing was chiefly decided on the basis of the callus formation at the fracture site and type of the fracture. In unstable fracture weight bearing was delayed until satisfactory callus formation, where in stable fracture patterns weight bearing was started early, to be initiate with partial weight bearing.

\section{Evaluation}

Postoperatively X rays (Standard Antero-posterior and Lateral views) were taken of the operated limb. The result of the treatment of femoral shaft fractures by using interlocking intramedullary nail AO type were assessed by Thoresen's criteria ${ }^{[27]}$ and Lower Extremity Functional Scale ${ }^{[28]}$ at the $1^{\text {st }}, 3^{\text {rd }}$ and $6^{\text {th }}$ month of the operation.

\section{Result Analysis}

The present study was conducted in the department of orthopedics at, AIMSR, Chittoor, Andhra Pradesh between 1January-2016 to 31-May-2017.

Probability value less than $5 \%$ was considered as statistically significant. The SPSS 17.0 software package (SPSS, Inc., Chicago, Illinois) was used for analysis. Microsoft Word and Excel were used to generate graphs and tables

A total number of 2082 fractures were admitted in our department between January 2016 and May 2017. Of these $1085(52.11 \%)$ were lower limb fractures, $856(41.11 \%)$ were upper limb fractures and $141(6.78 \%)$ were other factures that include spine, pelvis etc. Of the lower limb fractures $337(31.05 \%)$ were femoral fractures. Of the Femoral fractures $137(40.65 \%)$ were femoral shaft fractures.

The youngest in our series is 18 years old and the oldest is 60 years. Maximum numbers of patients in this study are of young reproductive group and mean age is 33.70 years. 64 patients were male $(82.1 \%)$ and the remaining were females (17.9\%). 47 Patients presented with right femoral shaft fractures (60\%), 31 had left femoral shaft fractures (40\%). 65 patients $(83.3 \%)$ had history of road traffic accident, remaining presented with slip and fall $(16.7 \%) .7$ patients had open fracture $(9 \%)$, remaining $71(91 \%)$ had closed fracture shaft of femur.

\section{The following results were obtained.}

Table 1: Thoresen's criteria in our study

\begin{tabular}{|c|c|c|c|c|c|}
\hline & & Frequency & Percent & Valid Percent & Cumulative Percent \\
\hline \multirow{4}{*}{ Valid } & Good & 57 & 73.1 & 73.1 & 73.1 \\
\cline { 2 - 6 } & Moderate & 12 & 15.4 & 15.4 & 88.5 \\
\cline { 2 - 6 } & Fair & 5 & 6.4 & 6.4 & 94.9 \\
\cline { 2 - 6 } & Poor & 4 & 5.1 & 5.1 & 100.0 \\
\cline { 2 - 6 } & Total & 78 & 100.0 & 100.0 & \\
\hline \multicolumn{5}{|c|}{$\sim 497 \sim$}
\end{tabular}


Table 2: Lower extremity functional score progression over a period of 6 months and ANOVA test

\begin{tabular}{|c|c|c|c|c|c|c|}
\hline \multicolumn{7}{|c|}{ ANOVA } \\
\hline & & Sum of Squares & df & Mean Square & $\mathbf{F}$ & Sig. \\
\hline \multirow{3}{*}{ LEFS 1st month } & Between Groups & 62.321 & 8 & 7.790 & .336 & .949 \\
\hline & Within Groups & 1600.512 & 69 & 23.196 & & \\
\hline & Total & 1662.833 & 77 & & & \\
\hline \multirow{3}{*}{ LEFS 3rd month } & Between Groups & 642.603 & 8 & 80.325 & .845 & .566 \\
\hline & Within Groups & 6556.077 & 69 & 95.016 & & \\
\hline & Total & 7198.679 & 77 & & & \\
\hline \multirow{3}{*}{ LEFS 6th month } & Between Groups & 372.802 & 8 & 46.600 & .518 & .839 \\
\hline & Within Groups & 6212.583 & 69 & 90.037 & & \\
\hline & Total & 6585.385 & 77 & & & \\
\hline
\end{tabular}

Objective outcome assessment done in form of lower extremity functional assessment over a period of 6 months shows positive correlation and good progression with $\mathrm{p}$ values progressing from 0.949 at 1 month, 0.566 at 3 months and 0.839 at the end of 6 months all together is less than 0.05 nullifying hypothesis that indicates good objective outcome progression over a period of time with stabilization of the fracture shaft of femur by reamed intramedullary nail.
Radiological outcome was statistically matched with the subjective and objective assessment with $\mathrm{p}$ value $<0.5$ so null hypothesis was rejected. The study is Indicative of direct relationship of the diameter of the nail and length of the nail spanning the fracture site. With the adequate length and the diameter used fracture union was earlier. So the diameter and the length of the nail used is one of the factors responsible for the early fracture healing.

Table 3: Radiological union and relation to the diameter and length of the nail used

\begin{tabular}{|c|c|c|c|c|}
\hline & & Length & Diameter & Radiological union(weeks) \\
\hline \multirow{4}{*}{ Length } & Pearson Correlation & 1 & $.440^{* * *}$ & -.220 \\
\cline { 2 - 5 } & Sig. (2-tailed) & & .000 & .053 \\
\cline { 2 - 5 } & $\mathrm{N}$ & 78 & 78 & 78 \\
\hline \multirow{4}{*}{ Diameter } & Pearson Correlation & $.440^{* *}$ & 1 & -.092 \\
\cline { 2 - 5 } & Sig. (2-tailed) & .000 & & .422 \\
\cline { 2 - 5 } & $\mathrm{N}$ & 78 & 78 & 78 \\
\hline \multirow{3}{*}{ Radiological union (weeks) } & Pearson Correlation & -.220 & -.092 & 1 \\
\cline { 2 - 5 } & Sig. (2-tailed) & .053 & .422 & \\
\cline { 2 - 5 } & $\mathrm{N}$ & 78 & 78 & 78 \\
\hline
\end{tabular}

The following complications were encountered in our study.

Table 4: Complications in our study

\begin{tabular}{|c|c|c|c|}
\hline $\begin{array}{c}\text { S. } \\
\text { No. }\end{array}$ & Complication & $\begin{array}{c}\text { Number of } \\
\text { Patients }\end{array}$ & Percentage \\
\hline 1 & Superficial infection & 5 & $6.41 \%$ \\
\hline 2 & Deep infection & 2 & $2.56 \%$ \\
\hline 3 & Delayed union & 2 & $2.56 \%$ \\
\hline 4 & Non- union & Nil & $0 \%$ \\
\hline 5 & Nail breakage & Nil & $0 \%$ \\
\hline 7 & Fat embolism & 1 & $1.28 \%$ \\
\hline 8 & Hematoma formation & 3 & $3.85 \%$ \\
\hline 9 & $\begin{array}{c}\text { Iatrogenic fracture neck } \\
\text { of femur }\end{array}$ & 1 & $1.28 \%$ \\
\hline
\end{tabular}

\section{Discussion}

The incidence of femoral shaft fractures was $6.5 \%$ per 100000 populations after excluding fractures below 18 years of age and above the 60 years of age, Patients below the age of 18 years and above 60 years, irregular follow-ups, Patients having neurovascular deficiency of the concerned limb, patients with immunosuppression -pharmacological or disease induced, having neuropsychological ailments, neurological deficiency due to any cause leading to postoperative mobilization difficulty, refusing to take treatment, deformity of at least one lower limb i.e. Polio, major joint contractures, and amputees, other fracture on the same limb or the other limbs 78 patients were selected for the present study. Most of our patients were of younger age group, $36(46.15 \%)$ patients between $20-30 y r s$, average age being 33.7 years, which correlate the fact that younger population is at increased risk of femoral fractures. Compared to the other studies in past our mean age group involved is slightly higher.

Table 5: Mean age compared to various studies

\begin{tabular}{|c|c|c|}
\hline Serial number & Previous studies & Mean age \\
\hline 1 & Wiss at el $^{13}$ & 29 \\
\hline 2 & ${\text { Thoresen's at } \mathrm{el}^{27}}^{17}$ & 28 \\
\hline 3 & Mukherjee D. $\mathrm{A}^{31}$ & 29 \\
\hline 4 & Meena RC & 35 \\
\hline 5 & Our study & 33.7 \\
\hline
\end{tabular}

The objective and functional outcome didn't show any difference in the outcome based on the age and gender of the patient.

In our series the level of fracture is dominated by AO type A3 with 29(37.2\%) out of 78 patients followed by A2 type $12(15.4 \%)$ out of 78 patients. Other reported series of conventional nailing, this figured ranged from $60-80 \%$ and $50 \%$ in the series of Thoresen ${ }^{[27]}$ et al. Fracture pattern in our study was transverse in $16(53.33 \%)$ out of 30 patients, 10 (33.3\%) comminuted, 2(6.66\%) spiral and 2(6.66\%) oblique. In the study of Thoresen ${ }^{[27]}$ et al. comminuted fractures were the common followed by transverse and then the spiral pattern. In the series of Wiss ${ }^{[12]}$ et al. comminuted fractures predominated. 
According to our studies the objective and subjective functional classification was independent $\mathrm{AO}$ classification system. Except the complication were more in the fracture who had segmental shaft of femur fracture (AO type C2)

In our study we had compared the subjective outcome with the objective outcome. In form of comparison of the Thoresen's criteria and lower extremity functional score, that showed comparable results.

Admission - operation interval in our study varied from 1-2 days. Except the delayed presentation of the cases most of the cases were operated within 48 hours of the admission. Before taking the patient for surgery, basic quantification of systemic inflammation and resuscitation was done. Mean interval being 24 hours. The optimal time for nailing of closed femoral diaphysis fractures has been suggested by Brumback et al. (1988) [16] as 7-10 days for elective admissions and immediately for patients with polytrauma to allow prompt mobilization. The mean duration of hospital stay in our study was 16 days average which is high when compared to Wiss ${ }^{[13]}$ et al. series where it was 12 days only and relatively low compared to Gross \& Kempf ${ }^{[9]}$ series (21 days). Intra operatively reduction was achieved by closed means in $26(86.6 \%)$ cases and $4(13.3 \%)$ needed open reduction due to late operation interval.

Table 6: Results from Series of Closed and Open Femoral Fractures Treated by Unreamed Antegrade Femoral Nailing

\begin{tabular}{|c|c|c|}
\hline & $\mathbf{N}$ & Union (weeks) \\
\hline Clatworthy et al. ${ }^{[15]}$ & 23 & 39.4 \\
\hline Kröpfl et al. ${ }^{[3]}$ & 81 & 16.5 \\
\hline${\text { Giannoudis } \text { et al. }{ }^{[34]}}^{[35]}$ & 13 & 26.9 \\
\hline Reynder and Broos & 53 & 19.2 \\
\hline Our study & 78 & 18 \\
\hline
\end{tabular}

The average time of radiological union was 18 weeks in the present study whereas in Gross Kempf et al. (1985) ${ }^{[9]}$ and in Thoresen et al. (1985) ${ }^{[27]}$ series it was 18 weeks and 16 weeks respectively. The average union rate was same in our series compared to the series of the above authors but with Wiss et al. (1986) ${ }^{[13]}$ it is 26 weeks which is very high compared to ours. Union time was 39.4 weeks In a series of Claworthy et al. ${ }^{[15]}$, who had used AO undreamed nail, compared to our study of reamed intramedullary nail, where the radiological union time is 18 weeks.

In various studies done for the reamed intramedullary nail showed In our study patient was partially weight bearing immediate post-operative period depending on the fracture pattern, while patients were not allowed weight bearing until 6 weeks on effected limb in a Thoresen ${ }^{[27]}$ et al. series (30 days).

Table 7: Results from Series of Closed and Open Femoral Fractures Treated by Reamed Antegrade Intramedullary Nailing

\begin{tabular}{|c|c|c|}
\hline & $\mathbf{N}$ & Union (wk) \\
\hline${\text { Johnson } \text { et al. }{ }^{[36]}}^{[9]}$ & 24 & 13.8 \\
\hline Kempf et al. ${ }^{\left[{ }^{26}\right.}$ & 52 & 19.5 \\
\hline Christie et al. ${ }^{[6]}$ & 120 & 17 \\
\hline Brumback et al. ${ }^{[16]}$ & 87 & 19 \\
\hline Søjbjerg et al. ${ }^{37]}$ & 40 & 12 \\
\hline Alho et al. ${ }^{[38]}$ & 123 & 13 \\
\hline Wiss et al. ${ }^{[13]}$ & 33 & 32 \\
\hline Clatworthy et al. ${ }^{[15]}$ & 22 & 28.6 \\
\hline Reynder and Broos ${ }^{[35]}$ & 54 & 19.6 \\
\hline Our study & 78 & 18 \\
\hline
\end{tabular}

2 of our case developed delayed-union with instability at the fracture site and needed augmentation plating and bone grafting. 1 of our patient had developed fracture neck of femur intra-operatively that was managed with the intraoperative lag screw fixation. All the patients in this study had no problems relating to malalignment, stiff knee and pain. No case reported with shortening which is very low compared to GROSS and Kempf ${ }^{[9]}$ where $11(21.1 \%)$ patients out of 52 had shortening.

There was a direct relationship of the diameter of the nail used and length of the nail used to the fracture union. Bigger the diameter and more the length used for nailing the fracture union was early.

\section{Conclusion}

The fractures of the shaft of femur are commonly seen in the young adult male population with Road traffic accidents. Right side was commonly involved than the left side. According to AO fracture Classification type A3 was the commonest type of fracture.

In the postoperative period, from the first postoperative day if there are no associated injuries, patients were started active knee movement and non-weight bearing walk with help of two elbow crutches and can be discharged from the hospital by the first week. Most of the fractures in our study were fixed within 48 hours which however showed excellent to good outcome, and other studies also have stressed upon fixation within 24 hours of injury.

The complications that arose were due to associated comorbidities or the compound fracture patterns or in the segmental fracture AO type $\mathrm{C} 2$ was most common associated with the delayed union which required secondary procedure in form of augmentation plating and bone grafting. Most of our patients achieved good range of movement at 2 months postoperatively with active exercise regimen.We like to point out that the subjective and objective assessment by the Thoresen's criteria and lower extremity functional scale respectively show equal functional outcome following the fracture shaft of femur stabilisation.

\section{References}

1. Bucholz, Robert W, James Heckman D, Charles CourtBrown M. Rockwood and Green's Fractures In Adults. 1st ed. Philadelphia: Wolters Kluwer Health, 2012. Print.

2. Farill, Incas and Aztecs used resinous wooden pegs in the medullary canal of long bones for treatment of nonunions (J, J.B.J.S:) 1956; 30A:506,

3. Watson Jones. Operative reduction of fractures chapter 16 in Watson jones fractures and joint injuries $16^{\text {th }}$ edition, 387.

4. Küntscher G. Praxis der Marknagelung. Stuttgart, Germany, F.K. Schattaur Verlag, 1961.

5. Thakur AJ. Intramedullary nailing chapter 5 in The elements of fracture fixation" Churchill livington New York, 1977.

6. Rush, Rush HL. Techniques for longitudinal pin fixation of long bone fractures of ulna and femur JBJS 1937; 21:619.

7. John Stewart DM, Jeffrey Hellett P. traction and orthopaedic appliances, second edition, chap 3, 18-20.

8. Weller, Hontsch D. medullary nailing of femur, tibia chapter 4, manual of internal fixation AO-ASIF $3^{\text {rd }}$ edition. Muller ME allogower springer-verlag New York, 1990, 291.

9. Kempf I, Grosse A, Beck G. Closed locked 
intramedullary nailing. Its application to comminuted fractures of the femur. J Bone Joint Surg Am. 1985; 67:709-720.

10. Winquist, Hansen. Communited fracturesof femoral shaft treated by IM nailing “OLNA. 1980; 11(3):633-48,

11. Charles Taylor J. Fractures of lower extremity" chap 23 in campbells operative orthopaedics, Crenshaw A.H. St. Louis mosby year book, 1994, 758-894.

12. Lhowe DW. Immediate nailing of open \# of femoral shaft, JBJS 1988, 70A:812-820

13. Wiss DA, William W, Brien, William B. Stetson, Interlocking nailing for treatment of segmental fractures of femur JBJS. 1990; 72-A:724-728,

14. Grover J, Donald A. Wiss A prospective study of fractures of femoral shaft treated with static IM interlocking nail comparing one versus two distal screws" ortho, clin North America. 1995; 26:B9-146,

15. Clatworthy MG, Clare DI. Reamed versus unreamed femoral nails, A randomized prospective trial JBJS Br, may $1998,80 \mathrm{~B}(3): 76$

16. Brumback RJ, IM nailing of femur reamed v/s undreamed Journal American acad orth surgery. 2000; 2:83-90

17. Arazi M. Early weight bearing after statically locked reamed nailing - is it a safe procedure, Jour of trauma. 2001; 50(4):711-16,

18. Tigani D. Is dynamization always necessary? Archieve of orthopaedics and trauma surg. 2005; 29(2):94-98

19. Apostle KL. The effects of intraoperative positioning on patients undergoing early definitive care for femoral shaft fractures. J Orthop Trauma. 2009; 23(9):615621. doi: 10.1097/BOT.0b013e3181a6a941

20. James Stannard P. Comparision of functional outcome following intra medullary nailing of femur with piriformis fossa and greater trochanter entry points, JBJS. 2011; 93:1385-91

21. Duan X, Li T, Mohammed AQ, Xiang Z. Reamed intramedullary nailing versus unreamed intramedullary nailing for shaft fracture of femur: a systematic literature review. Archives of orthopaedic and trauma surgery. 2011; 131(10):1445-52.

22. Li AB, Zhang WJ, Guo WJ, Wang XH, Jin HM, Zhao YM. Reamed versus unreamed intramedullary nailing for the treatment of femoral fractures: A meta-analysis of prospective randomized controlled trials. Medicine. 2016; 95(29):e4248.

23. AO/ASIF manual of internal fixation Muller second edition, 1999.

24. Terry canale S, James Beaty H. Campbells operative orthopaedics, $12^{\text {th }}$ edition, 3 .

25. Jon C. Thompson, Netter's Concise Atlas of Orthopaedic Anatomy, Elsevier, 2008.

26. Charan J, Biswas T. How to Calculate Sample Size for Different Study Designs in Medical Research? Indian Journal of Psychological Medicine. 2013; 35(2):121-126. doi:10.4103/0253-7176.116232.

27. Thoresen. Interlocking nailing in femoral shaft fractures, a report of 48 cases JBJS 1985; 67(A):1313-20.

28. Binkley JM, Stratford PW, Lott SA, Riddle DL. The Lower Extremity Functional Scale (LEFS): scale development, measurement properties, and clinical application. North American Orthopaedic Rehabilitation Research Network. Phys Ther. 1999; 79(4):371-83.

29. Yeung TS, Wessel J, Stratford P, Mac Dermid J. Reliability, validity, and responsiveness of the lower extremity functional scale for inpatients of an orthopaedic rehabilitation ward. Journal of orthopaedic \& sports physical therapy. 2009; 39(6):468-77.

30. Johnson KD. Biomechanical performance of locked IM nail system clin. Orth 1984; 206:151-161,

31. Mukherjee D. A Comparative Study of Management of Fracture Shaft of Femur by Open versus Closed Intramedullary Interlocking Nailing. Indian Medical Gazette, 2015, 191. 